\title{
Establishment of basic techniques related to protein sample preparation for neutron scattering
}

\author{
Aya Okuda, Rintaro Inoue, Ken Morishima, Yasuhiro Yunoki, Masahiro Shimizu, Nobuhiro Sato, \\ Reiko Urade, Masaaki Sugiyama \\ Institute for Integrative Radiation and Nuclear Science, Kyoto University, Kumatori, Sennan-gun, Osaka, Japan \\ okuda.aya.5r@kyoto-u.ac.jp
}

Proteins are bio-macromolecules that are responsible for various biological phenomena. Their functional expression takes place in the intracellular environment, i.e., the solution environment, which is a multi-component system with multiple proteins. Solution scattering is an effective method for structural analysis in such an environment. Particularly, in order to selectively analyze the structure of a specific protein in a multi-component system, the "inverse contrast matching small-angle neutron scattering (iCMSANS)" method is valuable utilizing the characteristics of neutron scattering, in which the scattering lengths of hydrogen and deuterium differ greatly [1]. In this method, when deuterated and hydrogenated proteins are observed in $\mathrm{D}_{2} \mathrm{O}$ solvent, the deuterated proteins become scatteringly invisible due to contrast matching, and only the scattering of the hydrogenated proteins be observed. For this analysis, it is necessary to prepare the proteins whose the degree of deuteration is precisely controlled to $75 \%$.

We have prepared $75 \%$ deuterated proteins using E. coli expression system and established a simple and rapid method to measure the degree of deuteration of proteins by mass spectrometry using MALDI-TOF MS. We also established a precise and simple method to measure the $\mathrm{D}_{2} \mathrm{O} / \mathrm{H}_{2} \mathrm{O}$ ratio of the solvent using the measurement by Fourier transform infrared spectroscopy (FT-IR) [2]. By using these techniques, we were able to obtain the accurate degree of deuteration of the proteins and $\mathrm{D}_{2} \mathrm{O} / \mathrm{H}_{2} \mathrm{O}$ ratio in the solvent, and match out the deuterated protein very well.

[1] Sugiyama, M., Yagi, H., Yamaguchi, T., Kumoi, K., Hirai, M., Oba, Y., Sato, N., Porcar, L., Martel, A. \& Kato, K. (2014). J. Appl. Crystallography 47, 430-435.

[2] Okuda, A., Inoue, R., Morishima, K., Saio, T., Yunoki, Y., Yagi-Utsumi, M., Yagi, H., Shimizu, M., Sato, N., Urade, R., Kato, K. \& Sugiyama, M. (2021). Biophys. Physicobiology. 18, 16-27.

Keywords: neutron scattering; protein deuteration; contrast matching method 